\title{
Assessment of Surgical Outcome and Complications between Spinal and General Anaesthesia for Patients Undergoing Percutaneous Nephrolithotomy: A Comparative Study
}

\author{
Atanu Mukherjee ${ }^{1}$, Gagandeep Singh ${ }^{2}$ \\ ${ }^{1}$ Assistant Professor, Department of Anesthesiology, Muzaffarnagar Medical College, Muzaffarnagar, Uttar Pradesh, India, ${ }^{2}$ Associate Professor, \\ Department of Anesthesiology, Muzaffarnagar Medical College, Muzaffarnagar, Uttar Pradesh, India.
}

\section{Abstract}

Background: Percutaneous nephrolithotomy (PCNL) is the treatment of choice for large renal calculi, staghorn calculi and calculi which fail treatment with extracorporeal shockwave lithotripsy and ureteral endoscopy. Hence; the present study was planned to compare the efficacy of spinal and general anaesthesia for patients undergoing percutaneous nephrolithotomy. Subjects and Methods: A total of 40 patients were included in the present study and were broadly divided into two study groups as follows: Group A: Included patients who underwent percutaneous nephrolithotomy under spinal anaesthesia; Group B: Included patients who underwent percutaneous nephrolithotomy under general anaesthesia. In both the study group patients, their respective type of anaesthesia was delivered. Percutaneous nephrolithotomy was carried out in all the patients. During the procedure, hemodynamic parameters were monitored. Patients were called for follow-up at regular intervals. Results: Non- significant results were obtained while comparing the occurrence of intraoperative complications in between subjects of group A and group B respectively. Mean hospital stay was 9 days for the subjects of group A and 13 days for the subjects of the group B. Significant results were obtained while comparing the mean hospital stay among both the study groups. However; while comparing the surgical outcome in between the two study groups, non- significant results were obtained. Conclusion: Both spinal and general anaesthesia can be used with equal effectiveness in patients undergoing percutaneous nephrolithotomy.

Keywords: Spinal, General anaesthesia, Percutaneous nephrolithotomy.

Corresponding Author: Dr. Atanu Mukherjee, Assistant Professor, Department of Anesthesiology, Muzaffarnagar Medical College, Muzaffarnagar, Uttar Pradesh, India.

Received: May 2019

Accepted: June 2019

\section{Introduction}

Urinary tract stone disease is a major health-care problem, and after urinary tract infections and prostate pathology, is the third in rank among the diseases of the urinary system. Percutaneous nephrolithotomy (PCNL) is the treatment of choice for large renal calculi, staghorn calculi and calculi which fail treatment with extracorporeal shockwave lithotripsy and ureteral endoscopy. ${ }^{[1-3]}$ PCNL is used for larger renal stones of size more than $20 \mathrm{~mm}$, staghorn stones and stones that are multiple or resistant to extracorporeal shock. PCNL can be done under local, general or regional anaesthesia. The literature mention that GA has many advantages over Regional Anaesthesia (RA) in term of better haemodynamic control, airway control, better patient and surgeon satisfaction. ${ }^{[4-7]}$

Hence; the present study was planned to compare the efficacy of spinal and general anaesthesia for patients undergoing percutaneous nephrolithotomy.

\section{Subjects and Methods}

The present study was conducted in the department of general surgery and anaesthesia of the medical institute and it included assessment and comparison of efficacy of spinal and general anaesthesia for patients undergoing percutaneous nephrolithotomy. Ethical approval was obtained from institutional ethical committee and written consent was obtained after explaining in detail the entire research protocol. A total of 40 patients were included in the present study and were broadly divided into two study groups as follows:

Group A: Included patients who underwent percutaneous nephrolithotomy under spinal anaesthesia;

Group B: Included patients who underwent percutaneous nephrolithotomy under general anaesthesia.

\section{Inclusion criteria for the present study included:}

- Subjects more than 18 years of age,

- Subjects with presence of renal stones larger than $15 \mathrm{~mm}$,

- Subjects with absence of any other systemic illness,

- Subjects with negative history of any known drug allergy

Detailed demographic data and clinical details of all the 
subjects were obtained. Preoperative biochemical profile of all the patients was obtained. In both the study group patients, their respective type of anaesthesia was delivered. Percutaneous nephrolithotomy was carried out in all the patients. During the procedure, hemodynamic parameters were monitored. Patients were called for follow-up at regular intervals. All the details were recorded in Microsoft excel sheet and were analysed by SPSS software. Chi- square test was used for assessment of level of significance. P-value of less than 0.05 was taken as significant.

\section{Results}

The present study was planned for comparing of efficacy of spinal and general anaesthesia for patients undergoing percutaneous nephrolithotomy. A total of 40 patients were included in the present study and were broadly divided into two study groups depending upon the type of anaesthesia used; Group A and Group B. Mean age of the patients of the group A and group B was 48.2 and 47.2 years respectively. There were 11 males in group A while there were 10 males in group B. Mean weight of the subjects of group A and group B was $69.5 \mathrm{Kg}$ and $70.2 \mathrm{Kg}$ respectively. $164.8 \mathrm{~cm}$ was the mean height of the subjects of group A while 165.6 $\mathrm{cm}$ was the mean height of the subjects of the group B.

In the present study, among 12 subjects of group A and 11 subjects of group B, stone was located on left side, while among 8 subjects of group A and 9 subjects of group B, stone was located on right side.

Mean duration of surgery among subjects of group A and group B was 115.5 minutes and 112.3 minutes respectively. Intraoperative pain was present in 1 patient of group A while it was absent in group B. Intraoperative hypotension was present in 2 patients of group A while it was present in 1 patient of group B. Non- significant results were obtained while comparing the occurrence of intraoperative complications in between subjects of group A and group B respectively.

\section{Table 1: Demographic data}

\begin{tabular}{|l|l|l|}
\hline Parameter & Group A & Group B \\
\hline Mean age (years) & 48.2 & 47.2 \\
\hline Males & 11 & 10 \\
\hline Females & 9 & 10 \\
\hline Mean weight $(\mathrm{Kg})$ & 69.5 & 70.2 \\
\hline Mean height $(\mathrm{cm})$ & 164.8 & 165.6 \\
\hline
\end{tabular}

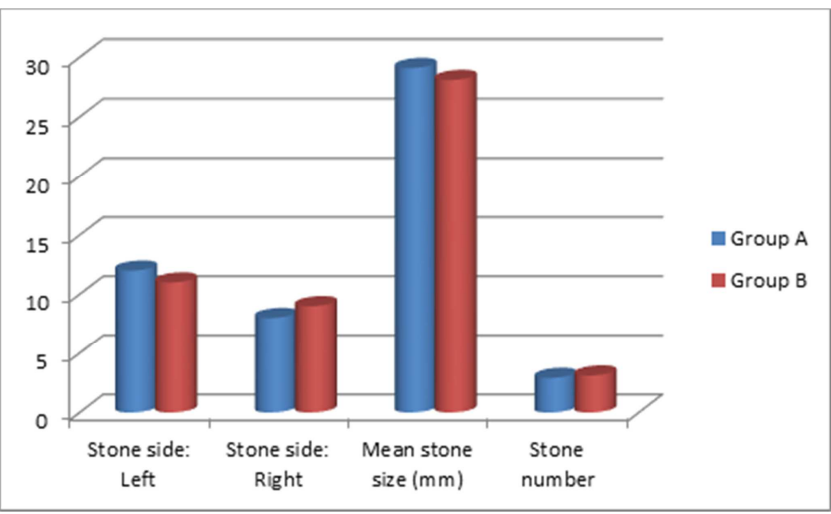

Figure 1: Stone characteristics
In the present study, postoperative pain was present in 6 patients of group A and 5 patients of group B. Postoperative fever was present in 10 patients of group A and 9 patients of group B. Mean hospital stay was 9 days for the subjects of group A and 13 days for the subjects of the group B. Significant results were obtained while comparing the mean hospital stay among both the study groups. However; while comparing the surgical outcome in between the two study groups, non- significant results were obtained.

\section{Table 2: Intraoperative events}

\begin{tabular}{|l|l|l|l|}
\hline Parameter & Group A & Group B & p- value \\
\hline $\begin{array}{l}\text { Duration of surgery } \\
\text { (minutes) }\end{array}$ & 115.5 & 112.3 & 0.25 \\
\hline $\begin{array}{l}\text { Presence of } \\
\text { intraoperative pain } \\
(\mathrm{n})\end{array}$ & 1 & 0 & 1 \\
\hline Hypotension (n) & 2 & 1 & 0.22 \\
\hline $\begin{array}{l}\text { Nausea vomiting } \\
(\mathrm{n})\end{array}$ & 2 & 0 & 0.51 \\
\hline Bleeding (n) & 2 & 2 & 0.11 \\
\hline
\end{tabular}

\begin{tabular}{|c|c|c|c|}
\hline Parameter & Group A & Group B & p- value \\
\hline $\begin{array}{l}\text { Postoperative pain } \\
\text { (n) }\end{array}$ & 6 & 5 & 0.36 \\
\hline $\begin{array}{l}\text { Postoperative fever } \\
\text { (n) }\end{array}$ & 10 & 9 & 0.74 \\
\hline $\begin{array}{l}\text { hospitalization } \\
\text { days }\end{array}$ & 9 & 13 & 0.00 (Significant) \\
\hline $\begin{array}{l}\text { Postoperative sore } \\
\text { throat (n) }\end{array}$ & 2 & 2 & 1 \\
\hline $\begin{array}{l}\text { Patient satisfaction } \\
\text { (n) }\end{array}$ & 18 & 17 & 0.22 \\
\hline
\end{tabular}

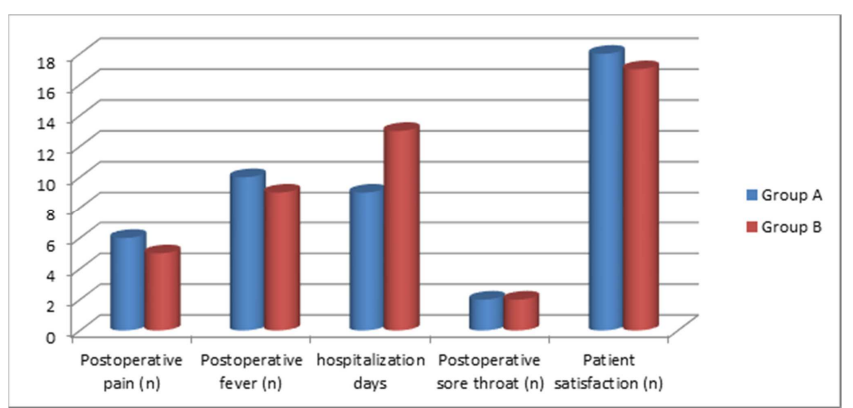

Figure 2: Comparative evaluation of post-operative pain, patient satisfaction, post-operative sore throat.

\section{Discussion}

Nowadays, percutaneous nephrolithotomy (PNCL) is a common method for extracting renal and urinary stones, and a choice modality in large, multiple, and stag-horn stones. Furthermore, PNCL can be used in patients with failed shock and endoscopic trials. In about $20 \%$ of cases, urologic procedures are undertaken with general anesthesia (GA) or regional anesthesia such as spinal anesthesia (SA) ${ }^{\left[{ }^{[-10]}\right.}$ Mean age of the patients of the group A and group B was 48.2 and 47.2 years respectively. There were 11 males in group A while there were 10 males in group B. Mean weight of the subjects of group A and group B was $69.5 \mathrm{Kg}$ and $70.2 \mathrm{Kg}$ respectively. $164.8 \mathrm{~cm}$ was the mean height of the subjects of group A while $165.6 \mathrm{~cm}$ was the mean height of the subjects of the group B. Movasseghi $\mathrm{G}$ et al compared the preference 
of spinal anaesthesia (SA) or general anaesthesia (GA) in respect to mentioned concerns. In this randomized clinical trial, 59 patients who underwent PCNL divided into SA and GA groups. $15-20 \mathrm{mg}$ from intra-thecal bupivacaine $0.5 \%$, and premedication of 0.01-0.02 $\mathrm{mg}$ from midazolam, were given to patients in SA group $(n=29)$. Patients in GA group $(\mathrm{n}=30)$ received premedication of $1-2 \mu \mathrm{g} / \mathrm{kg}$ from fentanyl and $0.01-0.02 \mathrm{mg} / \mathrm{kg}$ from midazolam, and intravenously anaesthetized with $100 \mu \mathrm{g} / \mathrm{kg} / \mathrm{min}$ of propofol and $0.5 \mathrm{mg} / \mathrm{kg}$ of atracurium, given by continuous infusion and $\mathrm{N} 2 \mathrm{O} / \mathrm{O} 2$ $50 \%$. Mean arterial pressure (MAP) and heart rate were recorded intra-operatively and during recovery. MAP and heart rate show no significant differences at designated time points between two groups $(\mathrm{P}>0.05)$. Surgery time, anesthesia time, bleeding volume, and analgesic intake were significantly reduced in SA group $(\mathrm{P}<0.05)$. It seems that, in patients undergoing PNCL, SA is as effective and safe as GA. ${ }^{[11]}$

In the present study, among 12 subjects of group A and 11 subjects of group B, stone was located on left side, while among 8 subjects of group A and 9 subjects of group B, stone was located on right side. Mean duration of surgery among subjects of group A and group B was 115.5 minutes and 112.3 minutes respectively. Intraoperative pain was present in 1 patient of group A while it was absent in group B. Intraoperative hypotension was present in 2 patients of group A while it was present in 1 patient of group B. Nonsignificant results were obtained while comparing the occurrence of intraoperative complications in between subjects of group A and group B respectively. Kamal M et al evaluated the feasibility of spinal anaesthesia in terms of intraoperative and postoperative results in patients undergoing PCNL. The total 1298 PCNL operations were done for kidney stone from January 2013 to December 2016, out of which 1160 patients underwent PCNL under SA while remaining 138 operations were carried out under GA in the prone position. The mean calculus size was $30.2 \pm 11.8 \mathrm{~mm}$. Return of sensory and motor activity in our study was $150.0 \pm 29.2$ minutes and $111.0 \pm 18.8$ minutes, respectively. In first 10 minutes of anaesthesia, 148 (12.75\%) patients developed hypotension, which was managed by ephedrine 6 $\mathrm{mg}$ intravenously (IV). Total seventy two patients $(6.2 \%)$ needed blood transfusion and $32(2.75 \%)$ complained of headache, dizziness and low back pain for two to four days after the operation, which improved with analgesics and bed rest. Ninety percent of the patients had complete clearance of calculus or there were no significant residual calculi larger than $5 \mathrm{~mm}$ on follow up ultrasonography. It can be concluded from their study that spinal anaesthesia is the safe and effective method of anaesthesia for PCNL in adult patients. ${ }^{[12]}$

In the present study, postoperative pain was present in 6 patients of group A and 5 patients of group B. Postoperative fever was present in 10 patients of group A and 9 patients of group B. Mean hospital stay was 9 days for the subjects of group A and 13 days for the subjects of the group B. Significant results were obtained while comparing the mean hospital stay among both the study groups. However; while comparing the surgical outcome in between the two study groups, non- significant results were obtained. Shah $\mathrm{R}$ et al compared the safety and efficacy of spinal anaesthesia and general anaesthesia in PCNL. In a randomized prospective study 60 patients were divided in two groups; group $1(n=30)$ underwent PCNL in general anaesthesia and group $2(n=30)$ underwent PCNL in spinal anaesthesia in prone position with the conventional technique. There was no significant difference between the complications regarding the anaesthesia. Post-operative nausea and vomiting were significantly higher in group 1 and headache in group 2 $(p=<0.001)$. Overall patient satisfaction rate was higher in group 2 then in group $1(\mathrm{p}=0.01)$. Hospital stay in group 1 was $5.27 \pm 1.87$ days and $4.53 \pm 1.88$ days in group $2(\mathrm{p}=$ $0.07)$. Stone success rate was similar in each group $(\mathrm{p}=0.50)$. Spinal anaesthesia is a safe and effective method in performing PCNL. ${ }^{[13]}$

\section{Conclusion}

Under the light of above obtained data, the authors conclude that both spinal and general anaesthesia can be used with equal effectiveness in patients undergoing percutaneous nephrolithotomy. However; further studies are recommended for better exploration of results.

\section{References}

1. Stening SG, Bourne S. Supracostal percutaneous nephrolithotomy for upper pole caliceal calculi. J Endourol. 1998;12(4):359-62.

2. Huskisson EC. Measurement of pain. Lancet. 1974;2(7889):1127-31.

3. Lojanapiwat B, Prasopsuk S. Upper-pole access for percutaneous nephrolithotomy: comparison of supracostal and infracostal approaches. J Endourol. 2006;20(7):491-4. doi: 10.1089/end.2006.20.491.

4. Montamat SC, Cusack BJ, Vestal RE. Management of drug therapy in the elderly. N Engl J Med. 1989;321(5):303-09.

5. Hazem El Sayed Moawad, Ahmed S, El Hefnawy Spinal vs general anaesthesia for percutaneous nephrolithotomy: A prospective randomized trial. Egyptian Journal of Anaesthesia. 2015;31(1):71-75.

6. Aravantinos E, Karatzas A, Gravas S, Tzortzis V, Melekos M. Feasibility of percutaneous nephrolithotomy under assisted local anaesthesia: a prospective study on selected patients with upper urinary tract obstruction. Europeon Urology. 2007;51(1):224-28.

7. Karacalar S, Bilen CY, Sarihasan B, Sarikaya S. Spinal-epidural anaesthesia versus general anaesthesia in the management of percutaneous nephrolithotripsy. J Endourol. 2009;23(10):1591-97.

8. Jun-Ou J, Lojanapiwat B. Supracostal access: does it affect tubeless percutaneous nephrolithotomy efficacy and safety? Int Braz J Urol. 2010;36(2):171-6.

9. Kuzgunbay B, Turunc T, Akin S, Ergenoglu P, Aribogan A, Ozkardes H. Percutaneous nephrolithotomy under general versus combined spinal-epidural anesthesia. J Endourol. 2009;23(11):1835-8. doi: 10.1089/end.2009.0261.

10. Karacalar S, Bilen CY, Sarihasan B, Sarikaya S. Spinal-epidural anesthesia versus general anesthesia in the management of percutaneous nephrolithotripsy. J Endourol. 2009;23(10):1591-7. doi: 10.1089/end.2009.0224

11. Movasseghi G, Hassani V, Mohaghegh MR, et al. Comparison between spinal and general anesthesia in percutaneous nephrolithotomy. Anesth Pain Med. 2013;4(1):e13871. Published 2013 Dec 26. doi:10.5812/aapm.13871

12. Kamal M, Sharma P, Singariya G, Jain R. Feasibility and Complications of Spinal Anaesthesia in Percutaneous Nephrolithotomy: Our Experience. J Clin Diagn Res. 2017;11(6):UC08-UC11. doi:10.7860/JCDR/2017/26425.10111

13. Shah R1, Thapa AS2, Lamichhane N1, Kc SR1. Safety and Efficacy of Spinal Anaesthesia in Percutaneous Nephrolithotomy. JNMA J Nepal Med Assoc. 2016 Oct-Dec;55(204):61-66. 
Copyright: ( ) the author(s), publisher. Academia Anesthesiologica International is an Official Publication of "Society for Health Care \& Research Development". It is an open-access article distributed under the terms of the Creative Commons Attribution Non-Commercial License, which permits unrestricted non-commercial use, distribution, and reproduction in any medium, provided the original work is properly cited.

How to cite this article: Mukherjee A, Singh G. Assessment of Surgical Outcome and Complications between Spinal and General Anaesthesia for Patients Undergoing Percutaneous Nephrolithotomy: A Comparative Study. Acad. Anesthesiol. Int. 2019;4(1):121-24.

DOI: dx.doi.org/10.21276/aan.2019.4.1.28

Source of Support: Nil, Conflict of Interest: None declared. 